\title{
Effect of heat treatment and laser surface remelting on AlSi10Mg alloy fabricated by selective laser melting
}

\author{
Quanquan $\operatorname{Han}^{1} \cdot$ Yang Jiao ${ }^{1}$ \\ Received: 5 July 2018 / Accepted: 27 December 2018 / Published online: 14 February 2019 \\ (C) The Author(s) 2019
}

\begin{abstract}
The selective laser melting (SLM) of aluminium alloys is of interest to researchers because of these alloys' potential applications in the aerospace and automotive domains. Post-processing is generally required in order to enhance the mechanical properties of devices that involve moving parts, where surface mechanical properties are significant factors. This paper describes a preliminary study that was conducted to investigate the effect of post-processing on the microstructure and mechanical properties of SLM fabricated AlSi10Mg alloy, with an emphasis on the laser surface remelting (LSR) process. The experimental results demonstrate that the heat treatment degraded tensile strength while improving ductility by achieving grain growth and residual stress release. The yield strength obtained in the experiment was reduced from 200 to $100 \mathrm{MPa}$, whereas the elongation increased from 6 to $22 \%$. The LSR process was found to contribute to an improvement in surface finish. The surface roughness indicator $R_{\mathrm{a}}$ was determined to be $0.93 \mu \mathrm{m}$ in the LSR post-processed sample, compared to a fairly high value of $19.3 \mu \mathrm{m}$ in the as-fabricated samples. The LSR process also enhanced the microhardness by refining the microstructure; the Si eutectic dendritic structure that formed was found to be finer than that of the as-fabricated samples. Compared to the as-fabricated samples, the LSR process contributed to a $19.5 \%$ increase in microhardness. The findings suggest that the microstructure and mechanical properties of SLM-fabricated AlSi10Mg parts could be tailored by suitable post-processing such as heat treatment and LSR. The significance of this research is its proposal of a novel technique to enhance surface hardness using LSR, which is a significant step towards the combination of SLM and LSR processes to manufacture customised aluminium components for the automotive and aerospace sectors.
\end{abstract}

Keywords Selective laser melting $\cdot$ Aluminium alloys $\cdot$ Heat treatment $\cdot$ Laser surface remelting $\cdot$ Microstructure

\section{Introduction}

Aluminium and its alloys are increasingly applied within the aerospace and automotive industries because of these materials' lightweight and high specific strength [1-4]. Among such alloys, AlSi10Mg is a traditional cast alloy that is widely used for die-casting. The alloy exhibits good weldability due to the near-eutectic composition of $\mathrm{Al}$ and $\mathrm{Si}$ elements [5]. The addition of $\mathrm{Mg}(0.3-0.5 \mathrm{wt} \%)$ contributes to hardening by forming $\mathrm{Mg}_{2} \mathrm{Si}$ precipitates upon natural or artificial ageing treatment [6].

Quanquan Han

HanQ1@ @ardiff.ac.uk

1 Cardiff School of Engineering, Cardiff University, Cardiff CF24 3AA, UK
Fabricating highly customised functional components such as those applied in the aerospace and automotive sectors is a challenge when using traditional manufacturing technologies such as casting, forging, and machining. Additive manufacturing (AM), a rapidly developing and advanced manufacturing technology, provides an integrated way to fabricate three-dimensional complex-shaped components from computer-aided design models [7-9]. Among the most advanced AM technologies, selective laser melting (SLM) is a widely used process for manufacturing complex metallic parts [10-12]. Several recent studies have reported the microstructure and mechanical properties of SLM-fabricated AlSi10Mg alloys. For instance, Kempen et al. [13] studied the mechanical properties of AlSi10Mg produced by SLM and found that the SLM-fabricated AlSi10Mg parts exhibited higher tensile strength and hardness than the casted parts; these parts were also found to offer anisotropy at breakage 
under different building directions. Brandi et al. [14] studied the microstructure and fatigue performance of SLM-fabricated AlSi10Mg under different directions $\left(0^{\circ}\right.$, $45^{\circ}$, and $90^{\circ}$ ). The authors found that the post-heat treatment had the most notable effect on fatigue resistance, while the building direction had the least notable effect. Thijs et al. [6], who investigated the texture of SLMfabricated AlSi10Mg samples, found that the texture could be controlled by the process parameters: a strong fibrous texture could be changed into a weak cube texture along the building and scanning directions when a rotation of $90^{\circ}$ of the scanning vectors between the layers was applied.

More recently, Read et al. [5] studied the influence of process parameters on porosity development in the SLM of AlSi10Mg alloys using a statistically designed experimental approach. The authors found that the laser power, scanning speed, and the interaction between the scanning speed and hatch spacing had a pronounced effect on porosity development; their creep results also showed better rupture life than cast alloy. Maskery et al. [15] employed $\mathrm{X}$-ray computed tomography to quantitatively study the porosity of SLM as-fabricated and heat-treated AlSi10Mg alloys. The authors found that the pore size and shape distributions were not affected by the heat treatments; even the annealing caused significant coarsening of the microstructure and a reduction in hardness. In addition, the largest pores were found to be anisotropic, being flat and disc-like in the XY plane (i.e. perpendicular to the building direction). Palumbo et al. [16] employed a nested effects modelling technique to investigate the effect of different laser exposure strategies on the physical and mechanical properties of AlSi10Mg fabricated by direct metal laser sintering. Del Re et al. [17] used one-way analysis of variance to assess the effect of powder reuse on the mechanical properties and surface quality of AlSil0Mg parts. The authors found that the effect of powder reuse was statistically significant in terms of yield strength and ultimate tensile strength.

Other researchers $[18,19]$ have also systematically investigated the effects of heat treatment on the microstructure and mechanical properties of SLM-fabricated AlSi10Mg. These studies have found that heat treatment reduces microhardness by softening the material. The $\mathrm{Si}$ atoms are precipitated from the Al matrix to form small Si particles rather than the eutectic dendrite microstructure found in the as-fabricated samples, which leads to a decrease in tensile strength of the heattreated samples.

The aforementioned studies have examined the microstructure and mechanical properties of as-fabricated and/or heattreated AlSi10Mg samples. Heat treatment has been found to improve ductility but also degrades strength by forming coarse Si particles. In several practical applications (in particular, devices that involve moving parts), surface mechanical properties such as hardness play a significant role in determining the life and performance of the assemblies, which implies that heat treatment might not be a suitable post-process to enhance SLM-fabricated AlSi10Mg parts. Laser surface remelting (LSR), in contrast, is capable of producing a surface layer with strong metallurgical bonding to the substrate under rapid melting and solidification conditions. Significant grain refinement and microstructure uniformity with fine dendrites in the surface layer can be achieved using this process [20]. A number of studies have been conducted in recent years in which LSR was used to improve thermal fatigue resistance, wear behaviour, and adhesion resistance [21-23]. The LSR process has yet to be combined with metal additive manufacturing to enhance SLM-fabricated parts, however.

Accordingly, preliminary research was conducted in the present work to investigate the effects of LSR on changes in microstructure and mechanical properties among SLMfabricated AlSi10Mg samples. The study also examined heat-treated and as-fabricated AlSi10Mg samples in order to obtain a better understanding of the influences of post-

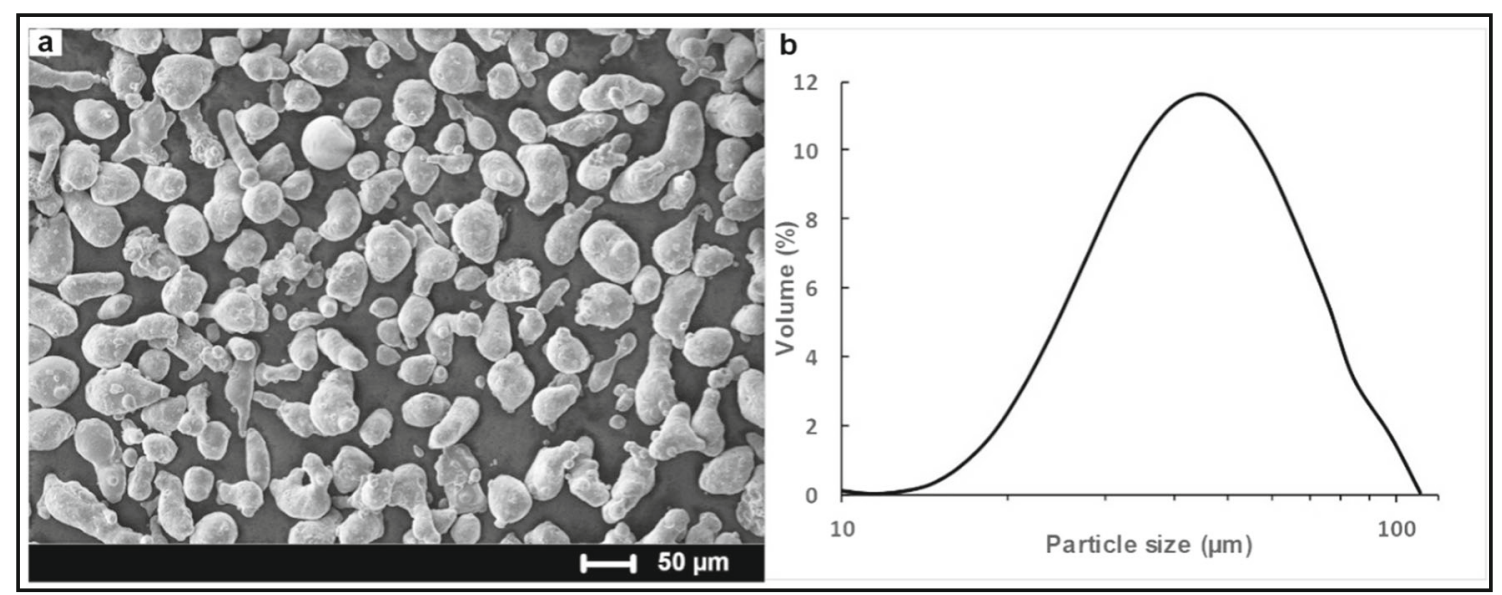

Fig. 1 Raw AlSi10Mg material (a) and the particle size distribution (b) 


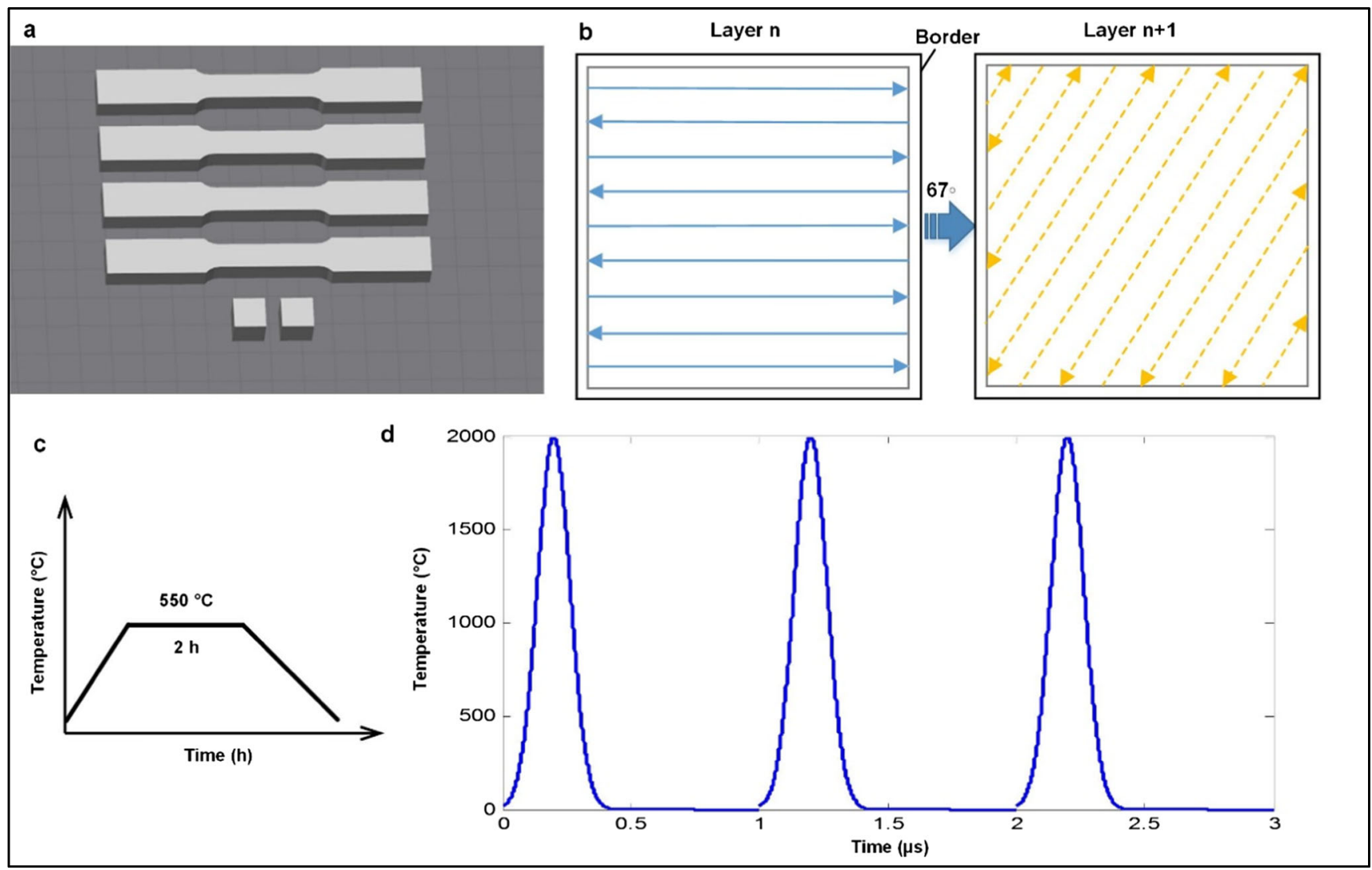

Fig. 2 Schematic of (a) printing job layout, (b) laser scanning strategy, (c) heat treatment strategy, and (d) pulsed laser for surface processing

processing. This study offers insights and practical advice on using heat treatment and laser surface remelting to tailor AlSi10Mg components manufactured by SLM.

\section{Materials and methods}

\subsection{Materials}

The raw AlSi10Mg material was obtained from Renishaw plc (Wotton-under-Edge, Gloucestershire, UK). Figure 1a shows the irregular shape of the raw powder with an average particle size (Dv[50]) of $43 \mu \mathrm{m}$ (Fig. 1b), measured using a Malvern Mastersizer 3000 (Malvern, UK); the $\operatorname{Dv}(10)$ and $\operatorname{Dv}(90)$ values were 25.5 and $77 \mu \mathrm{m}$, respectively.

\subsection{Methods and characterisation techniques}

A Renishaw AM250 (Renishaw plc, Wotton-under-Edge, Gloucestershire, UK) SLM system that employs a modulated ytterbium fibre laser with a wavelength of $1071 \mathrm{~nm}$ was used to fabricate cubic $\left(10 \times 10 \times 10 \mathrm{~mm}^{3}\right)$ and tensile specimens under the optimum process parameters (laser power $200 \mathrm{~W}$, hatching spacing $130 \mu \mathrm{m}$, powder layer thickness $25 \mu \mathrm{m}$, and laser scanning speed $500 \mathrm{~mm} / \mathrm{s}$ ); the dimensions of tensile specimens were determined according to ASTM-E8/E8M- 13a [24]. The specimens were fabricated with a null build angle, and the main dimension was aligned with the build platform direction (Fig. 2a). A bidirectional scanning strategy with chessboard fill-hatch type scanning was employed for this study. The rotation angle between each adjacent layer was set to $67^{\circ}$ to eliminate the chance of scan lines repeating themselves directly on top of one another, thus creating poor material properties (Fig. 2b).

Figure $2 \mathrm{c}$ shows the heat treatment scenario. Half the tensile specimens were solution-treated at $550^{\circ} \mathrm{C}$ for $2 \mathrm{~h}$, followed by furnace cooling. Figure $2 \mathrm{~d}$ shows a schematic of the high-frequency pulsed laser used for LSR employed using a DMG Lasertec 40 SAUER machine (DMG MORI UK Ltd., UK). The optimum process parameters used in the LSR of the AlSi10Mg samples are shown in Table 1.

Table 1 Process parameters for laser surface remelting

\begin{tabular}{llll}
\hline Parameters & Value & Parameters & Value \\
\hline Laser power & $20 \mathrm{~W}$ & Max. energy & $0.39 \mathrm{~mJ}$ \\
Energy percentage & $20 \%$ & Frequency & $30 \mathrm{kHz}$ \\
Scanning speed & $300 \mathrm{~mm} / \mathrm{s}$ & Pulse duration & $140 \mathrm{~ns}$ \\
Beam diameter & $32 \mu \mathrm{m}$ & Layer no. & 10 \\
Layer thickness & $0.01 \mathrm{~mm}$ & & \\
\hline
\end{tabular}




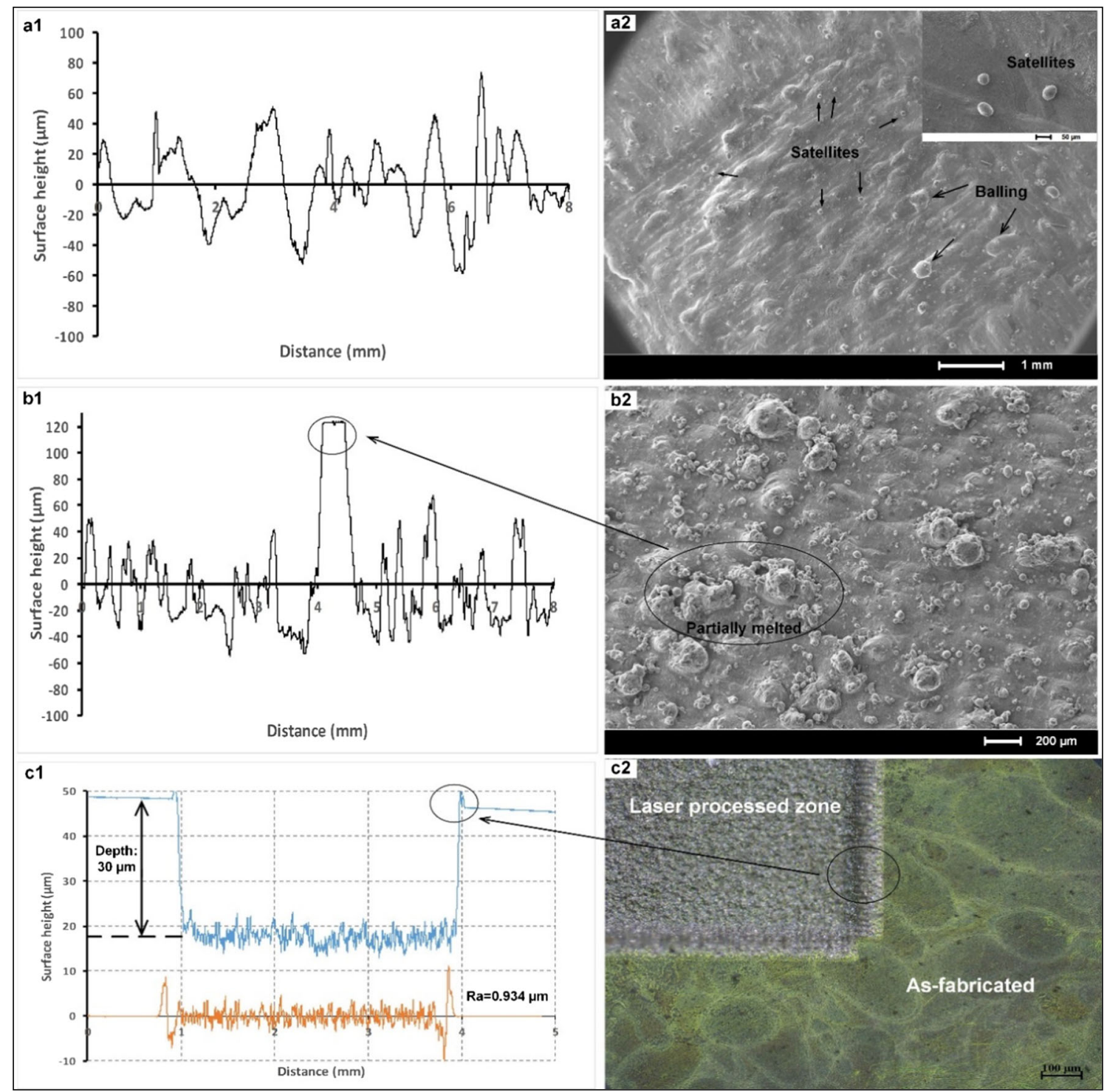

Fig. 3 Typical surface finish of the (a) top surface, (b) side surface, and (c) laser surface remelted surface

A Taylor Hobson surface finish tester was used to measure the roughness of the as-fabricated and LSR-processed surfaces under a $0.5 \mathrm{~mm} / \mathrm{s}$ measuring speed. A Gaussian filter was used to obtain $R_{\mathrm{a}}$ values for both as-fabricated and LSRprocessed surfaces. The roughness cutoff and evaluation length values were $2.5 \mathrm{~mm}$ and $12.5 \mathrm{~mm}$ for as-fabricated surfaces, while values of $0.8 \mathrm{~mm}$ and $4 \mathrm{~mm}$ were used for LSR-processed surfaces. For microstructure analysis, the samples were ground and polished using standard techniques prior to conducting optical microscopy $(\mathrm{OM})$ and scanning electron microscopy (SEM). The samples were etched using Keller's reagent for $20 \mathrm{~s}\left(190 \mathrm{ml}\right.$ distilled water, $5 \mathrm{ml} \mathrm{HNO}_{3}, 3 \mathrm{ml} \mathrm{HCl}$, $2 \mathrm{ml} \mathrm{HF}$ ) to reveal the microstructure. Vickers microhardness tests were performed using Innovatest (Maastricht, Netherlands) with a $100 \mathrm{~g}$ load and $10 \mathrm{~s}$ dwell time. Tensile tests were carried out at room temperature using a Zwick/ Roell tester with a strain rate of $1 \mathrm{~mm} / \mathrm{min}$.

\section{Results and discussion}

\subsection{Surface finish}

Figure 3 shows the surface finish of the as-fabricated and LSR-processed samples. (Because the heat treatment did not have a significant effect on the surface finish compared to the as-fabricated samples, the surface finish of the heat-treated samples is not shown in Fig. 3.) The typical top-surface finish of a cubic as-fabricated sample is shown in Fig. 3a1. The surface roughness indicator $R_{\mathrm{a}}$ was determined to be $19.3 \mu \mathrm{m}$. The top surface was also associated with a very limited number of balling and satellite defects (Fig. 3a2). The satellites were attributable to tiny amounts of unmelted metal powder, while the balling may have formed because of non-linear solidification. The high scanning speed generally promoted capillary instability in the molten pool, which led to 

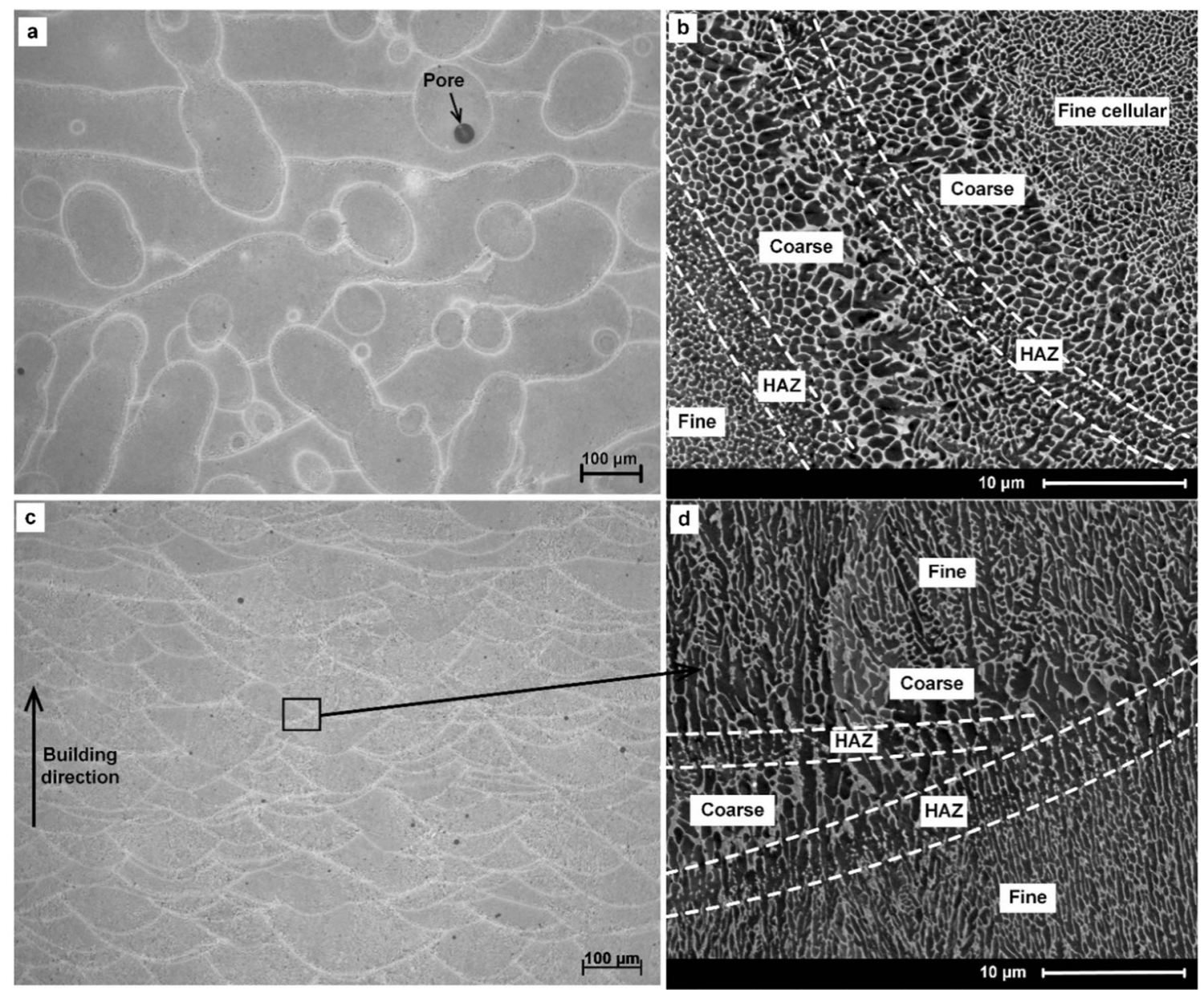

Fig. $4 \mathrm{OM}$ and SEM micrographs showing the microstructure of as-fabricated AlSi10Mg samples on (a and b) horizontal and (c and d) vertical sections

the splashing of small liquid droplets on the surface [25]; balling defects formed as a result. This balling led to an irregular surface shape, which in general is detrimental to subsequent powder deposition.

Figure $3 \mathrm{~b}$ shows the typical surface finish of the side surface; the $R_{\mathrm{a}}$ value was measured to be $27.5 \mu \mathrm{m}$. Compared to the top surface, a larger quantity of partially melted powder and a larger number of satellites have been observed on the relatively rough side surface. Figure $3 c$ shows the surface finish of the LSR-processed zone. Because of the repeated surface melting under very high laser frequency, some of the materials evaporated from the processed surface; the depth of the 'cavity' that formed was found to be about $30 \mu \mathrm{m}$. Compared to the as-fabricated top and side surfaces, the LSR process generated a much smoother surface finish, with an $R_{\mathrm{a}}$ value of $0.934 \mu \mathrm{m}$.

\subsection{Microstructure}

Figure 4 shows the microstructure of the as-fabricated samples in the horizontal and vertical sections. Figure 4a shows an OM photograph of the horizontal section, where the molten pools are clearly visible, with very limited pore formation. A cellulardendritic microstructure is visible in the SEM photograph, as shown in Fig. 4b. The Al-Si eutectic phase that formed was found to exhibit three different types of microstructure: fine, coarse cellular-dendritic, and heat-affected structure (HAZ). These formations are generally thought to be caused by the different solidification rates in the molten pool area along the direction of the thermal gradient. A similar observation has also been reported in the literature, where SLM has been employed to process aluminium alloys $[6,26,27]$.

The images in Fig. $4 \mathrm{c}$ and $\mathrm{d}$ show the microstructure of the vertical section, along with the build direction. The molten pool boundaries and the solidification-induced Al-Si eutectic microstructure along the building direction are clearly visible. The thermal gradient also led to grain elongation towards the centre of the molten pool, which led to the formation of columnar grains.

Figure 5 shows SEM micrographs of the post-processed samples. These images are useful for further investigation of the microstructure change under different post processes. Figure $5 \mathrm{a}$ and $\mathrm{b}$ show the microstructure of the heat-treated horizontal and vertical sections, respectively. Precipitated Si 


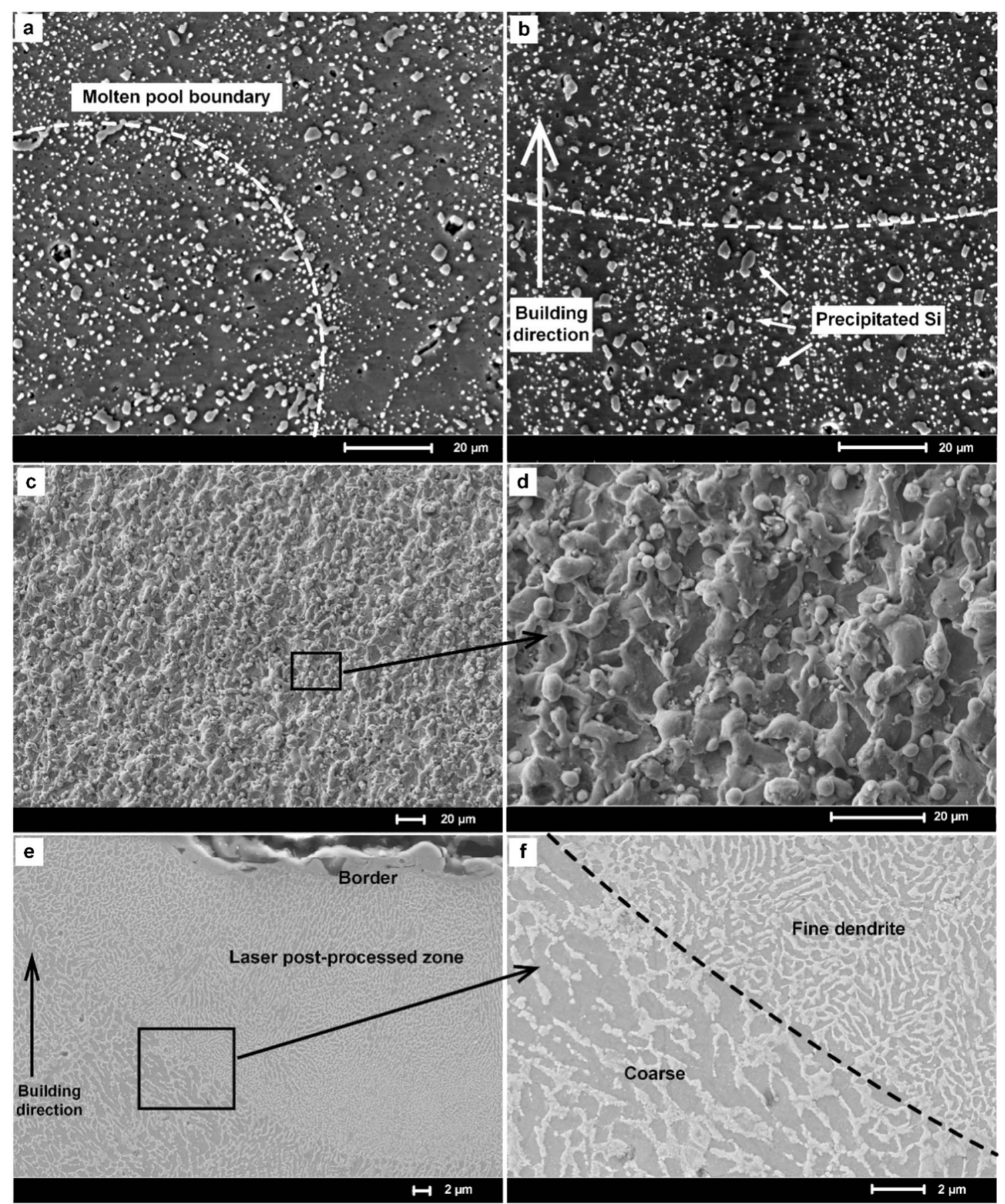

Fig. 5 SEM micrographs showing microstructure of (a) horizontal section, (b) vertical section of heat-treated sample, (c and d) LSR-processed surface, and (e and $\mathbf{f}$ ) cross-sectioned LSR-processed surface

particles were observed, which suggests that the Al matrix was supersaturated and that the excess Si precipitated to form Si particles under the heat treatment condition $\left(550^{\circ} \mathrm{C}\right.$ for $\left.2 \mathrm{~h}\right)$ [19]. It should be noted that the precipitated Si particles exhibited a relatively small size (less than $3 \mu \mathrm{m}$ ) and tended to agglomerate along the molten pool boundaries. Similar findings and detailed analysis have also been reported in the SLM of Al-12Si alloy [28].
The images in Fig. 5c-f show the microstructure of LSR-processed samples. Because of a large amount of surface remelting under high-frequency laser irradiation, an irregular meshlike structure formed on the processed surface (Fig. 5c and d). In other words, the laser irradiation generated heat energy following a Gaussian distribution, and the cooling rate within the molten pool varied due to the thermal gradient; some of the molten 


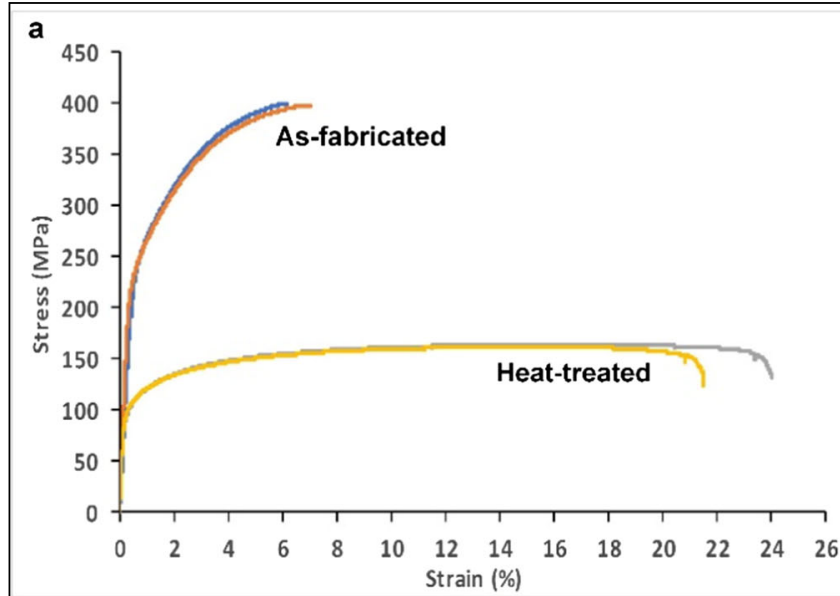

b

Fig. 6 Tensile stress-strain curves of as-fabricated and heat-treated AlSi10Mg samples (a); the samples after the tensile testing (b)

materials evaporated, while the remainder formed an irregular structure. The microstructure of the cross-section processed by LSR is shown in Fig. 5e and $\mathrm{f}$. The laser post-processed zone clearly exhibits a finer dendritic microstructure compared to the zone without laser processing. The uniformly distributed and finer microstructure could be explained by the rapid remelting and resolidification. This microstructure refinement could lead to enhanced surface mechanical properties such as microhardness and wear behaviour, which are significant factors in devices with moving parts.

\subsection{Mechanical properties}

Figure 6 shows the tensile testing results of the asfabricated and heat-treated AlSi10Mg samples. The tensile strength of the heat-treated samples showed an approximately $50 \%$ reduction in yield strength compared
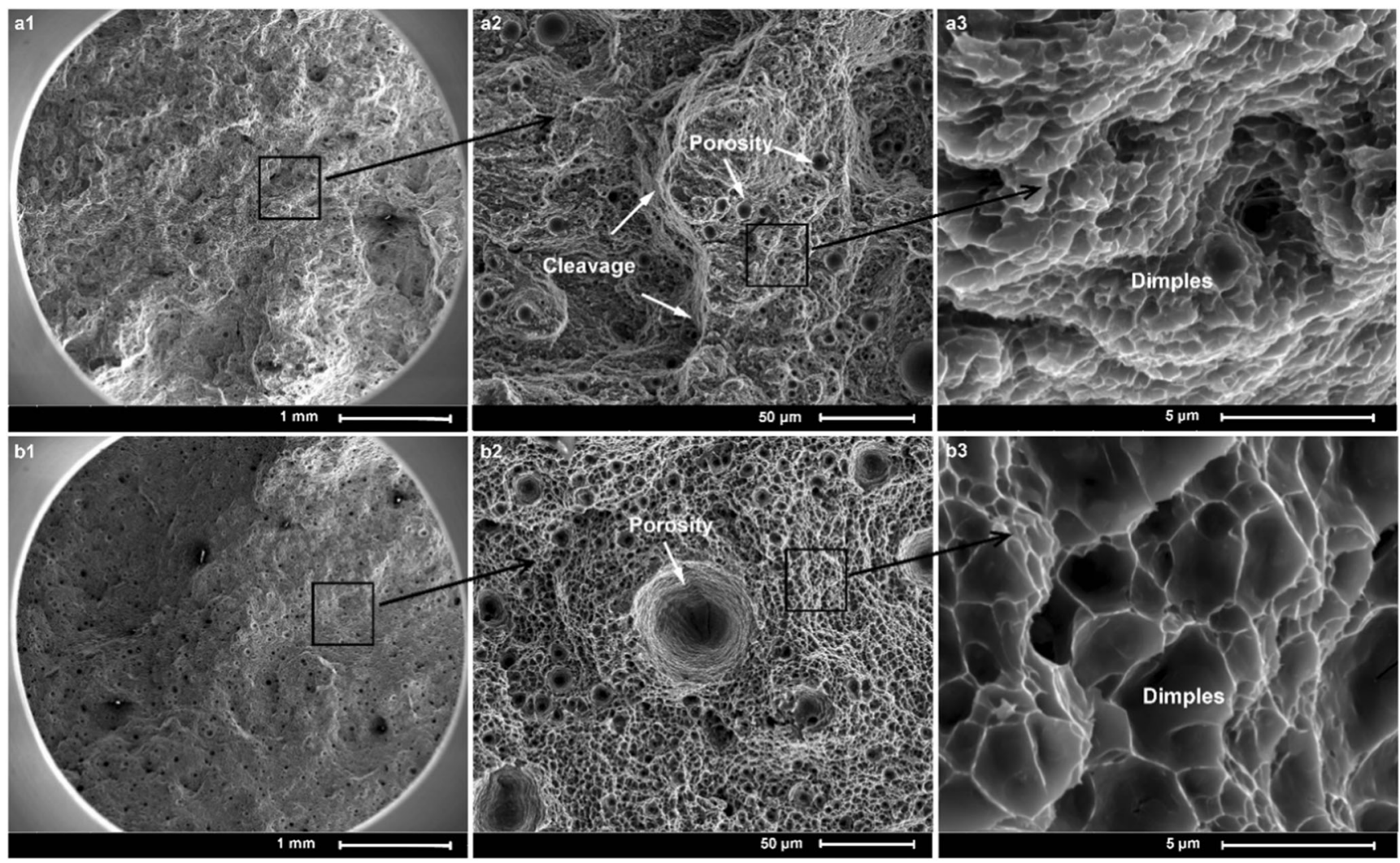

Fig. 7 SEM micrographs showing the fracture surfaces of (a) as-fabricated and (b) heat-treated tensile specimens 


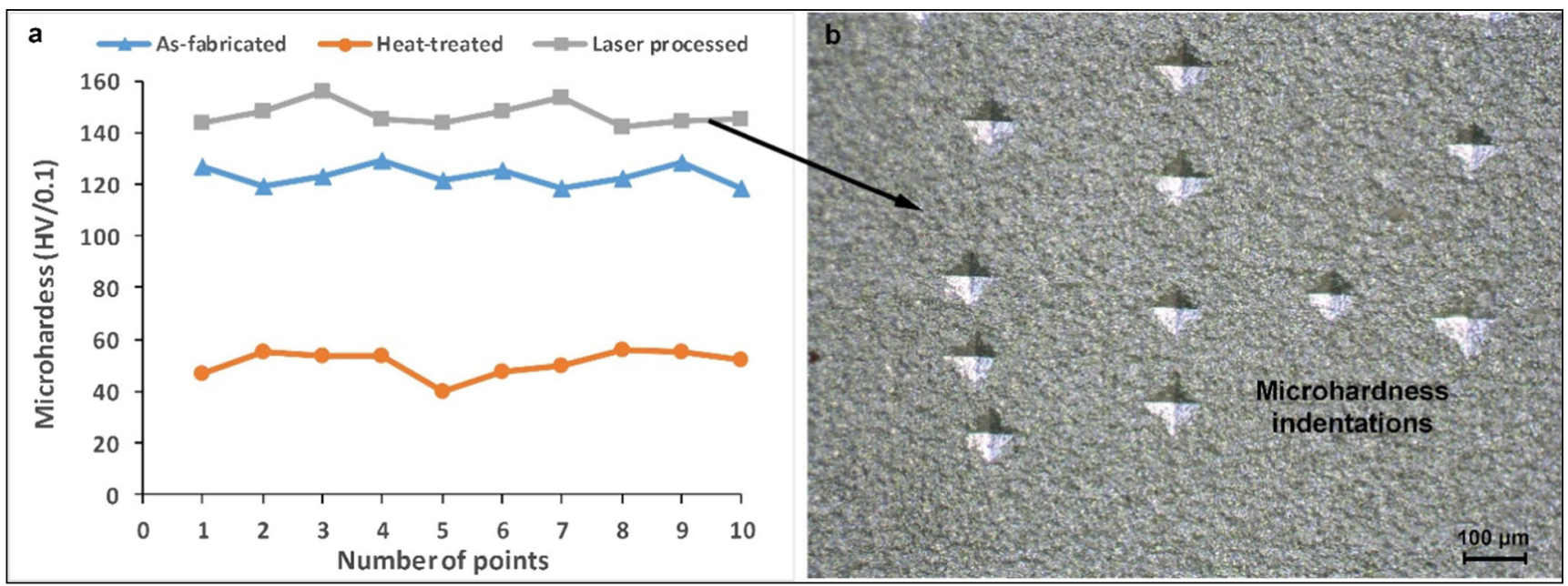

Fig. 8 Microhardness of the samples (as-fabricated, heat-treated, and LSR-processed)

to the as-fabricated samples, whose values were 100 and $200 \mathrm{MPa}$, respectively. The elongation was found to improve from 6 to $22 \%$. This change could be partly explained by the grain growth and $\mathrm{Si}$ precipitation during the solution heat treatment. Another factor that contributed to the improvement in ductility was the thermal residual stress release that occurred during heat treatment. The tensile specimens used in this study are shown in Fig. 6 b.

The fracture surfaces of the as-fabricated and heattreated tensile specimens are shown in Fig. 7. The pores that formed from the SLM process were opened due to uniaxial tension. The visible cleavage-fracture structure was caused by the fine anisotropic columnar grains and the residual stress that formed from the SLM process (Fig. 7a1-a3). The cleavage structure also tended to generate relatively brittle fracturing. This fracturing most likely propagated from the hatch overlaps, where the brittle $\mathrm{Si}$ phase density was higher than in other areas [28]. The heat treatment promoted grain growth, Si precipitation, and residual stress release, all of which led to the formation of a more uniform microstructure compared to the as-fabricated samples (Fig. 7b1-b3). It should be noted that the dimples in the heat-treated samples were larger than in the asfabricated samples, which may also be explained by the grain growth that took place during the heat treatment.

Figure 8 shows the microhardness of the as-fabricated, heat-treated, and LSR-processed samples. The polished cross-section for both as-fabricated and heat-treated specimens was measured. This cross-section was parallel to the build direction, while the LSR-processed cross-section was not subject to further polishing. The average microhardness of the as-fabricated samples was $123 \mathrm{HV} / 0.1$, while the value decreased to $51 \mathrm{HV} / 0.1$ when heat treatment was applied (Fig. 8a). The approximately $70 \mathrm{HV} / 0.1$ reduction in microhardness could be attributable to the grain growth, which reduced the grain boundaries. The effect of grain size on mechanical properties can be rationalised by the Hall-Petch relation [29].

The LSR-processed samples exhibited around $30 \mathrm{HV} / 0.1$ microhardness enhancement compared to the as-fabricated samples, which occurred because the high-frequency remelting and resolidification process generated a much finer microstructure. The grain refinement resulted in a reduction of the distance between Si particles. This behaviour increased the $\mathrm{Al}-\mathrm{Si}$ interface and significantly hindered dislocation movement. The nanoscale Si eutectic dendritic network that formed in the LSR-processed samples also enabled the release of localised shear stress. The microhardness improvements obtained in the LSR-processed sample was in agreement with the observed microstructure shown in Fig. 5e and f. Figure $8 \mathrm{~b}$ shows a photograph of the microhardness indentations measured in the LSR-processed sample.

\section{Conclusions}

This study has investigated the effect of post-processing on the microstructure and mechanical properties of SLMprocessed AlSi10Mg alloy, with an emphasis on the laser surface remelting process. This paper has presented the following important findings derived from the results.

1. Laser surface remelting contributed to improvements to the surface finish. The surface roughness indicator $R_{\mathrm{a}}$ was determined to be $0.93 \mu \mathrm{m}$ in the LSR-processed sample, compared to a fairly high value of $19.3 \mu \mathrm{m}$ in the asfabricated samples. The heat treatment did not have a significant effect on surface finish improvement, however.

2. The heat treatment degraded the tensile strength while improving the ductility of the SLM-processed AlSi10Mg samples by achieving grain growth and 
residual stress release. The yield strength was reduced from 200 to $100 \mathrm{MPa}$, while the elongation was increased from 6 to $22 \%$, which implies that the mechanical properties of the additive manufactured parts could be tailored by controlling the heat treatment conditions.

3. The high-frequency laser surface remelting enhanced the microhardness by refining the microstructure. The Si eutectic dendritic structure that formed was finer than the SLM as-fabricated samples. As a result, the LSRprocessed sample exhibited an approximately $19.5 \%$ increase in microhardness.

This study has indicated that post-processing is capable of altering both the microstructure and mechanical properties of SLM-processed AlSi10Mg parts. This work's findings, in combination with the design freedom allowed by additive manufacturing, are expected to expand the potential applications of metal additive manufacturing and post-processing in the aerospace and automotive sectors.

Acknowledgments The authors would like to thank Mr. Haiyang Fan from KU Leuven, Belgium, for the SEM operations and valuable discussions.

Open Access This article is distributed under the terms of the Creative Commons Attribution 4.0 International License (http://creativecommons.org/ licenses/by/4.0/), which permits unrestricted use, distribution, and reproduction in any medium, provided you give appropriate credit to the original author(s) and the source, provide a link to the Creative Commons license, and indicate if changes were made.

Publisher's note Springer Nature remains neutral with regard to jurisdictional claims in published maps and institutional affiliations.

\section{References}

1. Çam G, Koçak M (1998) Progress in joining of advanced materials. Int Mater Rev 43:1-44. https://doi.org/10.1179/imr.1998.43.1.1

2. Han Q, Geng Y, Setchi R, Lacan F, Gu D, Evans SL (2017) Macro and nanoscale wear behaviour of $\mathrm{Al}-\mathrm{Al} 2 \mathrm{O} 3$ nanocomposites fabricated by selective laser melting. Compos Part B Eng 127:26-35. https://doi.org/10.1016/j.compositesb.2017.06.026

3. Wong M, Tsopanos S, Sutcliffe CJ, Owen I (2007) Selective laser melting of heat transfer devices. Rapid Prototyp J 13:291-297. https://doi.org/10.1108/13552540710824797

4. Han Q, Gu H, Soe S, Setchi R, Lacan F, Hill J (2018) Manufacturability of AlSi10Mg overhang structures fabricated by laser powder bed fusion. Mater Des 160:1080-1095. https://doi. org/10.1016/j.matdes.2018.10.043

5. Read N, Wang W, Essa K, Attallah MM (2015) Selective laser melting of AlSi10Mg alloy: process optimisation and mechanical properties development. Mater Des 65:417-424. https://doi.org/10. 1016/j.matdes.2014.09.044

6. Thijs L, Kempen K, Kruth JP, Van Humbeeck J (2013) Finestructured aluminium products with controllable texture by selective laser melting of pre-alloyed AlSi10Mg powder. Acta Mater 61: 1809-1819. https://doi.org/10.1016/j.actamat.2012.11.052
7. Louvis E, Fox P, Sutcliffe CJ (2011) Selective laser melting of aluminium components. J Mater Process Technol 211:275-284. https://doi.org/10.1016/j.jmatprotec.2010.09.019

8. Han Q, Setchi R, Lacan F, Gu D, Evans SL (2017) Selective laser melting of advanced $\mathrm{Al}-\mathrm{Al} 2 \mathrm{O} 3$ nanocomposites: simulation, microstructure and mechanical properties. Mater Sci Eng A 698:162173. https://doi.org/10.1016/j.msea.2017.05.061

9. Han Q, Setchi R, Evans SL (2016) Synthesis and characterisation of advanced ball-milled $\mathrm{Al}-\mathrm{Al} 2 \mathrm{O} 3$ nanocomposites for selective laser melting. Powder Technol 297:183-192. https://doi.org/10.1016/j. powtec.2016.04.015

10. Gu DD, Meiners W, Wissenbach K, Poprawe R (2012) Laser additive manufacturing of metallic components: materials, processes and mechanisms. Int Mater Rev 57:133-164

11. Kruth JP, Froyen L, Van Vaerenbergh J et al (2004) Selective laser melting of iron-based powder. J Mater Process Technol 149:616622

12. Han Q, Mertens R, Montero-Sistiaga M et al (2018) Laser powder bed fusion of Hastelloy X: effects of hot isostatic pressing and the hot cracking mechanism. Mater Sci Eng A 732:228-239. https:// doi.org/10.1016/j.msea.2018.07.008

13. Kempen K, Thijs L, Van Humbeeck J, Kruth J-P (2012) Mechanical properties of AlSil0Mg produced by selective laser melting. Phys Procedia 39:439-446. https://doi.org/10.1016/j.phpro.2012.10.059

14. Brandl E, Heckenberger U, Holzinger V, Buchbinder D (2012) Additive manufactured AlSi10Mg samples using selective laser melting (SLM): microstructure, high cycle fatigue, and fracture behavior. Mater Des 34:159-169

15. Maskery I, Aboulkhair NT, Corfield MR, Tuck C, Clare AT, Leach RK, Wildman RD, Ashcroft IA, Hague RJM (2016) Quantification and characterisation of porosity in selectively laser melted Al-Si10Mg using X-ray computed tomography. Mater Charact 111:193204. https://doi.org/10.1016/j.matchar.2015.12.001

16. Palumbo B, Del Re F, Martorelli M et al (2017) Tensile properties characterization of AlSi10Mg parts produced by direct metal laser sintering via nested effects modeling. Materials (Basel) 10:144. https://doi.org/10.3390/ma10020144

17. Del Re F, Contaldi V, Astarita A et al (2018) Statistical approach for assessing the effect of powder reuse on the final quality of AlSi10Mg parts produced by laser powder bed fusion additive manufacturing. Int J Adv Manuf Technol 97:2231-2240. https:// doi.org/10.1007/s00170-018-2090-y

18. Aboulkhair NT, Maskery I, Tuck C, Ashcroft I, Everitt NM (2016) The microstructure and mechanical properties of selectively laser melted AlSi10Mg: the effect of a conventional T6-like heat treatment. Mater Sci Eng A 667:139-146. https://doi.org/10.1016/j. msea.2016.04.092

19. Li W, Li S, Liu J, Zhang A, Zhou Y, Wei Q, Yan C, Shi Y (2016) Effect of heat treatment on AlSi10Mg alloy fabricated by selective laser melting: microstructure evolution, mechanical properties and fracture mechanism. Mater Sci Eng A 663:116-125. https://doi.org/ 10.1016/j.msea.2016.03.088

20. Zhong M, Liu W, Zhang H (2006) Corrosion and wear resistance characteristics of $\mathrm{NiCr}$ coating by laser alloying with powder feeding on grey iron liner. Wear 260:1349-1355. https://doi.org/10. 1016/j.wear.2005.09.033

21. Tong X, Dai MJ, Zhang ZH (2013) Thermal fatigue resistance of H13 steel treated by selective laser surface melting and $\mathrm{CrNi}$ alloying. Appl Surf Sci 271:373-380. https://doi.org/10.1016/j. apsusc.2013.01.209

22. Chen L, quan RL, Zhao Y, Zhou H (2008) The wear-resistance of $3 \mathrm{Cr} 2 \mathrm{~W} 8 \mathrm{~V}$ steel with cave pit non-smooth surface processed by laser. J Bionic Eng 5:34-39. https://doi.org/10.1016/S16726529(08)60069-4

23. Shan H, Zhou H, Sun N, Ren L, Chen L, Li X (2008) Study on adhesion resistance behavior of sample with striated non-smooth 
surface by laser processing technique. J Mater Process Technol 199: 221-229. https://doi.org/10.1016/j.jmatprotec.2007.07.033

24. Standard test methods for tension testing of metallic materials. https://compass.astm.org/Standards/HISTORICAL/E8E8M-13A. htm. Accessed 15 Sep 2018

25. Zhang B, Liao H, Coddet C (2012) Effects of processing parameters on properties of selective laser melting $\mathrm{Mg}-9 \% \mathrm{Al}$ powder mixture. Mater Des 34:753-758. https://doi.org/10.1016/j.matdes.2011.06. 061

26. Kimura T, Nakamoto T (2016) Microstructures and mechanical properties of $\mathrm{A} 356$ (AlSi7Mg0.3) aluminum alloy fabricated by selective laser melting. Mater Des 89:1294-1301. https://doi.org/ 10.1016/j.matdes.2015.10.065
27. Li XP, Wang XJ, Saunders M, Suvorova A, Zhang LC, Liu YJ, Fang MH, Huang ZH, Sercombe TB (2015) A selective laser melting and solution heat treatment refined $\mathrm{Al}-12 \mathrm{Si}$ alloy with a controllable ultrafine eutectic microstructure and 25\% tensile ductility. Acta Mater 95:74-82. https://doi.org/10.1016/j.actamat.2015.05. 017

28. Prashanth KG, Scudino S, Klauss HJ, Surreddi KB, Löber L, Wang Z, Chaubey AK, Kühn U, Eckert J (2014) Microstructure and mechanical properties of $\mathrm{Al}-12 \mathrm{Si}$ produced by selective laser melting: effect of heat treatment. Mater Sci Eng A 590:153-160. https://doi. org/10.1016/j.msea.2013.10.023

29. Hansen N (2004) Hall-Petch relation and boundary strengthening. Scr Mater 51:801-806. https://doi.org/10.1016/j. scriptamat.2004.06.002 